\title{
RETRATOS QUE SENTEM: UMA ANÁLISE SOBRE O SINTOMA EM PIERRE FATUMBI VERGER
}

\author{
Daniela Cristiane Martins ${ }^{1}$
}

Resumo: O fotógrafo francês Pierre Verger realizou, entre as décadas de 40 a 60 , um trabalho etnográfico e antropológico entre a África e o Brasil sobre a cultura negra e suas ramificações. Com a intenção de manter essa cultura viva na busca por singularidade e simbolismo nas imagens, o objeto de trabalho de Verger foram os retratos. O propósito final desta pesquisa é refletir sobre tais retratos, presentes na obra "Orixás", analisados a partir do conceito de rosticidade, de Gilles Deleuze e Felix Guattari, e de sintoma, de Georges Didi-Huberman.

Palavras-chave: Retrato. Etnografia. Antropologia. Candomblé. Pierre Verger.

\section{PORTRAITS THAT FEEL: AN ANALYSIS OF THE SYMPTOM IN PIERRE FATUMBI VERGER}

Abstract: The French photographer Pierre Verger accomplished, between the decades of 40 and 60, an ethnographical and anthropological work between Africa and Brazil about the black culture and its ramifications. With the main purpose of keeping this culture alive in the quest for singularity and symbolism in the images. The aim of Verger's work were the portraits. The final purpose of this research is to reflect about such portraits found on "Orixa's" work analyzed from the concept of "rosticidade", by Gilles Deleuze and Felix Guattari, and of symptom, by Georges Didi-Huberman.

Keywords: Portrait. Ethnography. Anthropology. Candomblé; Pierre Verger.

\section{Pierre Verger: Nasce o Fatumbi}

Registros. Marcas de um povo, de uma história e da memória de uma cultura. Assim é o trabalho de Pierre Fatumbi Verger. Um homem que se tornou babalaô - e um babalaô que se tornou um etnólogo-antropólogo. As imagens registradas por Verger mostram toda a grandiosidade de uma cultura, capaz de resistir e renascer diante de

\footnotetext{
${ }^{1}$ Pós-graduada em Fotografia pela Universidade Do Vale do Itajaí - Univali. Graduada em Comunicação Social com habilitação em Publicidade e Propaganda pela Universidade Regional de Blumenau - Furb. Professora de Fotografia e Marketing na Uniasselvi (Brusque e Guaramirim) e Professora de Fotografia de Moda no SENAI de Blumenau e Região. Mestranda em Ciências da Linguagem da Universidade do Sul de Santa Catarina - Unisul, nascida em Blumenau/SC, Brasil. E-mail: dcm0412@gmail.com
} 


\section{Universidade do Extremo Sul Catarinense \\ Revista lbero-Americana de Humanidades, Ciências e \\ Educação \\ unesc

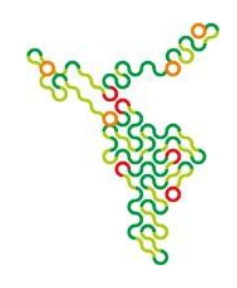

adversidades.

Francês, nascido em 1902 na cidade de Paris, Pierre Edouard Leopold Verger não enxergava muito futuro em sua cidade natal. De família rica, se viu sozinho aos 30 anos, após a morte da mãe, sua última parente viva; sua única companhia eram os amigos, entre eles Pierre Boucher. É este amigo que o ensina fotografia, pensada de início para ser um passatempo, mas que logo se revela uma paixão em sua vida, além de sua profissão. Decidido a buscar novos lugares e pessoas, partiu em viagem tendo sua câmera Rolleiflex como companheira.

O primeiro destino foi o Thaiti; depois foram 14 anos de intensas viagens com registros fotográficos singulares, carregados de técnica, mas também de muita liberdade, ousando não apenas nos cortes, mas também nos ângulos. Vendendo suas fotos para a imprensa, conseguiu se manter, além de contar com um financiamento que recebia do centro de pesquisas de Paris. Através destes trabalhos, se viu forçado a escrever sobre o que via e registrava. Foi um processo natural, mas o que o movia era, e sempre foi, o desejo de liberdade, como mostra Le Bouler, em uma passagem do próprio Verger:

\footnotetext{
Eu me pus a viajar, não tanto pelo desejo de fazer pesquisas etnográficas e trazer comigo reportagens, mas pela necessidade de me distanciar, de libertarme e fugir do meio onde havia vivido até então e cujos preconceitos e regras de conduta não me tomaram feliz [...]. Eu procurava o meu caminho fora da vida traçada pela minha família e acreditei por um momento que conseguiria satisfazer minhas aspirações ao adotar uma linha de conduta e atividades ditadas por um movimento extremista, antiburguês. (LE BOULER, 2002, p. $55)$.
}

Pierre Verger enxergou-se morador do mundo e a cada trabalho realizado foi se mostrando também um pesquisador e grande etnógrafo, mas sem título algum. Como havia abandonado os estudos aos 17 anos, jamais cogitou ser alguém com um diploma, porém isso não o impediu de realizar diversas pesquisas de muita relevância.

Começou suas viagens 1932 e a cada novo projeto, um novo lugar e assim, passou por aproximadamente 15 países. Porém, demorou muito para chegar ao Brasil, pisou em terras brasileiras em 1946 e, pela primeira vez, sentiu que não precisava partir logo. A Bahia já se mostrou interessente no dia em que leu o romance Jubiabá, de Jorge Amado e quando aqui chegou "foi logo seduzido pela hospitalidade e riqueza cultural que encontrou na cidade e acabou ficando", (COSTA, 2013).

Pouco tempo depois da sua chegada começou a trabalhar na revista $O$ Cruzeiro. 


\title{
Universidade do Extremo Sul Catarinense Revista Ibero-Americana de Humanidades, Ciências e Educação

Sentindo-se bem recebido e com um emprego, se aproxima do povo, com quem sempre se sentiu bem, e vê na Bahia um lugar que manteve a cultura negra com traços fortes da África. Ele se encanta com a maneira como as pessoas viviam e se relacionavam, fotografa tudo, sem interesse documental. Retrata a beleza dos homens e mulheres que recriam o continente africano na cidade. (AGUIAR, 2008).

Uniu seu trabalho às pessoas e à cultura pelas quais se sentiu abraçado e fez disto seu principal e mais rico registro. "Se debruçou sobre as culturas populares, [...] pois ele já percebia elementos de semelhança entre essas culturas e as culturas africanas, temas que mais tarde se tornaram o seu maior foco de atenção" (SANTOS, 2010, p.1). Toda pesquisa e interesse em nome da cultura afro o aproximaram cada vez mais dos ritos e tradições. Suas fotos sugerem uma entrega à cultura visual deste tempo, da influência dos costumes dos povos negros e deste encontro étnico que o interessava fotograficamente. Para Rolim (2002):

\begin{abstract}
A Bahia que Pierre Verger enxerga confirma suas ideias anteriores ao seu encontro com ela, mas, ao mesmo tempo, também acresenta coisas importantes para sua trajetória de vida. A imagem de Bahia que Verger vem a formar depois de certo tempo está ligada ao seu olhar, sua percepção e seu entendimento sobre as questões que o local lhe colocava. [...]. Verger quando de sua chegada e de como seu olhar "distraído" foi se voltando para as questões que envolviam os afro-descendentes locais, principalmente no que diz respeito aos assuntos relacionados ao candomblé (ROLIM, 2002, p.80).
\end{abstract}

Essa aproximação e permissão 'divina' só foram possíveis quando Mãe Senhora (Mãe de Santo em Salvador), “consagra sua cabeça a Xangô” (DEVOS, 1999, pag. 340). Ela o consagra para que ele possa falar em seu nome na África, lugar que iria viajar dias depois. Verger se instala na região de Ketu, na África Ocidental, atual Benin, e é neste local que vai dar forma a sua pesquisa, além de ressurgir dentro do candomblé, renascendo com o nome de Fatumbi, que significa "nascido de novo graças ao Ifá". É nesse momento que ele percebe toda a liberdade que tem para explorar de perto os cultos, registrando praticamente o mesmo ritual nos dois continentes.

Um babalâ̂, um sacerdote, um pai de santo dedicado e um fotógrafo-pesquisador extremamente curioso e organizado. O Fatumbi se mostra um verdadeiro etnógrafo, apresentando estudos riquíssimos e fotografias primorosas. Sua capacidade metodológica se apresenta já em sua primeira obra, Dieux d’Afrique, 1954, mas é no livro Orixás, que ele concretiza uma comparação sólida, visual e antropológica, apontando cada cerimônia 


\section{Universidade do Extremo Sul Catarinense \\ Revista Ibero-Americana de Humanidades, Ciências e \\ Educação \\ unesc

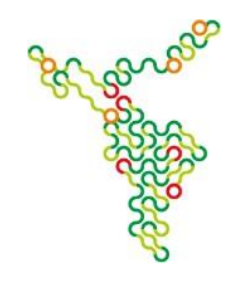

com imagens realizadas nos dois países. Jérôme Souty afirma este fato:

[...] ele mostra as semelhanças culturais e religiosas entre os dois lados do
Atlântico por meio de uma série de fotos colocadas lado a lado (figuras do
panteão, rituais, gestos, artesanato...), e por meio de montagens cruzadas (para
descrever visualmente um mesmo ritual ele mistura, na mesma seqüência,
imagens fotografadas na África e no Brasil). Nestes verdadeiros "ensaios
fotográficos", Verger conseguiu criar uma nova articulação entre imagem e
escritura. O seu acervo fotográfico, hoje alocado na Fundação Pierre Verger,
em Salvador, constitui uma formidável base de dados comparativos sobre as
culturas yoruba e fon e as suas diásporas, (SOUTY, 2007, p. 30).

Pierre Verger realiza novos projetos, novas pautas e mais fotos, mas mantém seu compromisso com a força e valor simbólico das culturas afros. Verger traça um panorama do candomblé e suas origens na África e a forma como a religião foi trazida, se desenvolveu e se constituiu no Brasil.

\section{Retratos: o registro de Verger}

Enquanto registro do real, as fotografias feitas entre os dois países, no livro “Orixás”, mostram a aproximação e a constituição de uma única nação marcada pela escravidão. Usar o retrato como "experiência de memória” (ALCÂNTARA, 2014) reforça a teoria de sintoma quando pensamos a fotografia como forma de registro de um tempo. As imagens feitas por Verger seguem nessa intenção: conservação de uma identidade e suas características religiosas e culturais. Para Pierre Verger, os povos iorubá (grupo étnico da África Ocidental) e afro-brasileiros eram 'sua gente', gostava de exaltar a beleza e a força, sempre os fotografando com imponência.

A intenção final desta pesquisa que se inicia é analisar os retratos existentes na obra "Orixás", relacionando-os aos conceitos de história sintomal, de Georges DidiHuberman, e de osticidade, de Gilles Deleuze e Félix Guattari. É sobre a ótica das leituras desses autores que desejamos olhar para as imagens, sempre tendo como memória a manifestação de uma crença.

As fotografias do livro "Orixás", que podem ser visualizadas dentro do acervo, no site da Fundação Pierre Verger, foram pensadas em dois grupos Retrato - Plano médio e geral e Retrato - Close. A intenção desta divisão é poder analisar com mais objetividade as imagens e a maneira como Verger fotografava. No primeiro grupo, em que o quadro é contemplado com um ângulo mais aberto, os personagens são enaltecidos, os conferindo poder e soberania. Esse recurso é conseguido por meio do contra-plongée (câmera 


\section{Universidade do Extremo Sul Catarinense \\ Revista Ibero-Americana de Humanidades, Ciências e \\ Educação \\ unesc

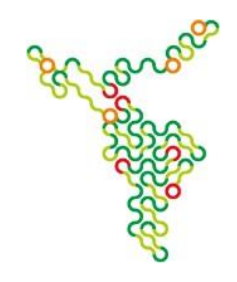

baixa/de baixo para cima), colocando o olhar das pessoas acima da linha da câmera, bem como nos explica Souty:

É importante mencionar que ele utilizava uma câmera Rolleiflex. Ela possui um visor no centro e trabalha com duas lentes, permitindo fazer o enquadramento sem ter a "câmera diante dos olhos, mantendo-a no nível do peito ou altura da barriga" (SOUTY, 2011 p.21).

Em algumas imagens, em que o elemento se encontra na linha do olhar do fotógrafo, ou até quando a pessoa não está olhando para a câmera, Verger clica um "semiperfil", característica utilizada por diversos fotógrafos que seguiam o movimento retratista. Santos (2010) demonstra que Pierre Verger buscava estímulo visual neste movimento, permitindo construir uma linha diagonal no espaço da fotografia. Santos nos aponta, ainda, uma relação entre as fotografias de Pierre Fatumbi com os retratos de Félix Nadar (francês, caricaturista, fotógrafo que viveu de 1820 a 1910), em que é possível ver que ambos não se posicionam de forma totalmente frontal ou totalmente lateral, criando uma sensação de movimento natural nas fotografias feitas por eles.

Seja plano médio, geral ou close, todo retrato define um espaço e uma noção de enquadramento - nem sempre condizentes com a realidade no que tange postura, vestes e adornos, mas sempre potencializando suas raízes. Senra (2009) explica esta característica quando descreve o trabalho de Claudia Andujar sobre o índios yanomamis: “... o retrato começa [...] de um enquadramento mais flexível, que permite [...] valorizar detalhes ou posturas peculiares e acentuar, [...], olhares que se dirigem à câmera" (SENRA, 2009, p. 134). De todas as fotografias de Verger, a grande maioria são retratos; o foco ao longo dessa pesquisa são os rostos/expressões - traços que possuem uma dinâmica própria e única, sempre contando muito mais do que conseguimos ver. Como apresentam Deleuze e Guattari em Ano Zero - Rosticidade: “É tudo precisamente porque o rosto depende de uma máquina abstrata que ele não se contentará em recobrir a cabeça, mas afetará as outras partes do corpo, e mesmo, se necessário, outros objetos sem semelhança”, (DELEUZE, GUATTARI,1996, p. 35).

\section{A importância da fotografia - A liberdade visual do Fatumbi}

Fotografias contam algo, trazem uma consciência e refletem uma história. Elas representam, de alguma forma, uma realidade, um agora, um contexto e uma versão dos fatos. Independente se são imagens de lugares ou pessoas, as fotos estão diretamente 


\section{Universidade do Extremo Sul Catarinense \\ Revista Ibero-Americana de Humanidades, Ciências e \\ Educação \\ unesc

ligadas com a nossa capacidade de rememorar. As imagens têm esse poder e servem como testemunha de um tempo, além de figurarem como pano de fundo na construção de boa parte da história/memória, como nos sugere Andrade (2002):

Foi atribuído à fotografia o peso de expressar o real, sendo a foto vista como uma espécie de prova, necessária e suficiente, que atesta a existência daquilo que é visto. Classificada por alguns ora como um simples instrumento de uma memória documental do real, ora como pura criação imaginária, a fotografia assume o papel de auxiliar a memória (ANDRADE, 2002, p.38).

Não é apenas como lembrança, mas como forma de sobrevivência e posicionamento perante à história que leremos as imagens de Pierre Verger no livro "Orixás". Os retratos figuram boa parte de seu trabalho e são eles que nos apresentam uma identidade cultural única, sem distinção de continente. Estes registros de representação dos povos servem muito mais como "legado", permitindo que a história daquele povo nunca morra. Um local eterno onde se pode retornar quando se desejar, independente de tempo ou espaço (ALCÂNTARA, 2014).

Dentre tantos registros fotográficos e estudos dos povos, qual seria o motivo de se valer do trabalho de Pierre Verger para apresentar um sintoma histórico? Qual a relevância que há nos retratos dos povos iorubás e afro-brasileiros que mereçam tal destaque? O que aqueles rostos falam e para quem falam? Como escrito, Verger se tornou Fatumbi ("nascido de novo graças ao Ifá”) em Ketu (África Ocidental) no mesmo momento em que se converte ao candomblé e vira pai de santo. Esse fato que permite sua aproximação dos cultos e rituais

de iniciação como nem um outro fotógrafo o fez. Essa liberdade - e mais o fato dele não ter uma preocupação aparente com a questão estética da fotografia - o tornaram único e deixou seu trabalho muito mais singular. Ele mesmo conta que por vezes abdicou dos padrões estéticos tendo como intenção a "espontaneidade das expressões e das cenas que podia capturar". Não sentia necessidade em seguir regras, o processo do trabalho era natural e seguia o fluxo das cenas a sua frente. Atitudes muito distintas do padrão europeu, que geralmente tende a se valer do "domínio consciente de seus atos", buscando o máximo de apuro técnico e visual (SOUTY, 2011, p.22/23). É essa postura, além do resultado alcançado no decorrer das décadas, que tornam a pesquisa relevante, pois por mais que se valesse de certos conceitos ou movimentos artísticos, ele jamais "copiava" ou se baseava no trabalho de outro artista. 


\section{Universidade do Extremo Sul Catarinense \\ Revista lbero-Americana de Humanidades, Ciências e \\ Educação \\ unesc

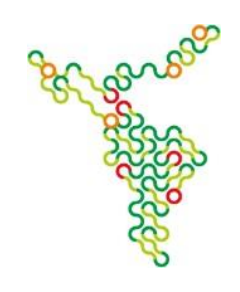

\section{$O$ rosto fala - $A$ imagem sente}

O rosto não é apenas aquilo que estamos vendo, ele é uma caixa de Pandora, um simulacro de nós mesmos, mas ainda assim diz que não pode ser "assimilado por conceitos" (MARQUES, 2015). O rosto é, quase sempre, a primeira coisa que avistamos do outro. Em um pré-julgamento é por meio dele que "decidimos" se aquela pessoa "serve" ou não. Isso ocorre muito rapidamente, como nos relatam Deleuze e Guatarri: "[...] a máquina abstrata de rosticidade assume um papel de resposta seletiva ou de escolha: dado um rosto concreto, a máquina julga se passa ou não, se vai ou não vai ..." (DELEUZE, GUATARRI, 1996, p.44).

Os rostos presentes nas imagens do livro "Orixás" não categorizam esse patamar, eles possuem um grau elevado de significação, pois advêm de uma cultura primitiva. Para Deleuze e Guattari, “os 'primitivos' podem ter as cabeças mais humanas, as mais belas e mais espirituais; eles não têm rosto e não precisam dele" (DELEUZE, GUATARRI, 1996, p.43). Eles servem como entonação para explicitar ações e aspectos culturais, expressivos e até mesmo políticos dentro da comunidade onde vivem.

Além dos rostos e suas significações, o trabalho que Pierre Verger realizou serve como documento para diversos fins etnográficos e antropológicos. Essa possibilidade nos permite fazer uma analogia com a "história sintomal" que acreditamos existir por trás deles. Uma intenção não apenas documental, mas um grito de sobrevivência e perpetuação.

É importante mencionar que sintoma é um termo advindo do campo da psicanálise, debatido por teóricos como Freud e Lacan. Para Freud, sintoma refere-se a um resultado de um "conflito psíquico, como mensagem do inconsciente"; já para Lacan, o sintoma é “ [...] como mensagem-metáfora; como gozo e como invenção-criação" (FONTES, MAIA, MEDEIROS, 2012).

Por muito tempo, o registro por meio da fotografia era privilégio de poucos e restrito a uma parte hierárquica da sociedade, como nos lembra Didi-Huberman:

Uma vez que o retrato - antigo e humanista - se nega duas vezes a representar
os povos: uma primeira vez pelo fato de fundamentar-se em uma hierarquia
social e uma divisão política na qual os homens de poder são os únicos
imputados com o privilégio de "existir em imagens" (nesse sentido, a
representação dos "persona"//"people"/"pessoas" nas revistas populares de
nossos dias aparece como comprovação dessa divisão: se dirige aos povos,
como destinatários passivos, como uma representação à qual não têm direito
como sujeito com todas as premissas da lei (DIDI-HUBERMAN, 2014, p.55). 


\section{Universidade do Extremo Sul Catarinense \\ Revista lbero-Americana de Humanidades, Ciências e \\ Educação \\ unesc

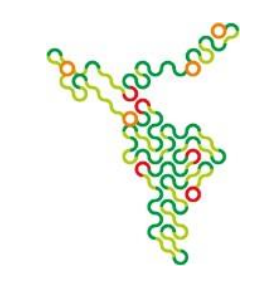

Não era essa a sociedade que interessava a Pierre Verger - e seu trabalho é prova disso. Quando ele deseja que o mesmo sirva de "memória", ele tem consciência de que essa intenção pode sofrer mudanças por parte da própria história. Não há controle sobre tal evolução ou até mesmo "adaptações", como a que ocorreu com os africanos quando foram separados de sua terra natal, mas não de suas crenças. "A história das imagens é perpassada por aparições, sobrevivências, pois a cultura - [...] - é uma coisa "viva" (DIDIHUBERMAN, 2013, p.285).

A câmera é o elemento de ligação entre o retrato e o sintoma de sobrevivência, principalmente quando há tanto ainda a ser visto, pensado e respeitado. Collier (1973) mostra, aos olhos de um antropólogo visual, a importância na memória por meio da imagem:

As impressões guardadas apenas com a vista humana perdem a nitidez,
fundem-se com outras impressões e, com o tempo, desaparecem. Quando você
utiliza a câmara, é possível reunir um modelo complexo, que contém
literalmente milhares de elementos concretos a serem comparados...
(COLLIER, 1973, p. 30).

O sintoma nas imagens da obra "Orixás", bem como de todo registro de Verger, seguem uma "fórmula de sobrevivência". "Que o sintoma funciona, [...], como funciona a imagem, [...], um conjunto, sempre novo e surpreendente, de "restos vitais" da memória. (DIDI-HUBERMAN, 2013, p.273).

O fato de identificar nos retratos da obra "Orixás” uma autonomia na capacidade de perpetuar uma etnia, de forma atemporal, faz deles narrativas sociais. As imagens que compõem a obra "Orixás" são uma amostra da riqueza visual, força identitária e "seus aspectos [...] culturais, indiciais, ou expressivos" (MARQUES, 2015), capazes de nortearem as expectativas da pesquisa proposta.

\section{Referências}

AGUIAR. Joselia. O corpo das ruas: A fotografia de Pierre Verger na construção da Bahia ioruba. São Paulo, 2008. Disponível em:< www.teses.usp.br/teses/disponiveis/8/8138/tde-07042009.../JOSELIA_AGUIAR.pdf>. Acessado em 10 de maio de 2019.

ANDRADE, Rosane de. Fotografia e Antropologia. Olhares fora-dentro. São Paulo. Editora Estação Liberdade Ltda, 2002. 


\section{Universidade do Extremo Sul Catarinense \\ Revista Ibero-Americana de Humanidades, Ciências e \\ Educação

unesc

ALCÂNTARA, Paulo Augusto Franco de. Antropologia da Pode: Os Retratosde

Família no Espaço Rural em Minas Gerais. Rio de Janeiro. Disponível em:< http://www.29rba.abant.org.br/resources/anais/1/1401127049_ARQUIVO_RBAAntrop ologia daPose.pdf >. Acessado em 20 abr. 2019.

COSTA, Ialê Menezes Leite. Pierre Verger (1932-1948): Caminhos da

fotoreportagem. Porto Alegre-RS, 2013. Disponível em:

file://C:/Users/Daniela/Desktop/Ial\%C3\%AA\%20Menezes\%20Leite\%20Costa.pdf>.

Acessado em 10 de maio de 2017.

COLLIER, Jonh, Jr. Antropologia Visual: a fotografia como metódo de pesquisa. Coleçao antropologia e sociologia. São Paulo: Editora da Universidade de São Paulo, 1973.

DELEUZE, Gilles; GUATTARI, Félix. Mil Platôs: Capitalismo e Esquizofrenia 3. Rio de Janeiro: Editora 34, Ed.V, 1996.

DIDI-HUBERMAN, Georges. A Imagem Sobrevivente. História da arte e tempo dos fantasmas segundo Aby Warburg. Rio de Janeiro. Editora: Contraponto. 2013.

DIDI-HUBERMAN, Georges. Pueblos expuestos, pueblos figurantes. Buenos Aires. Editora: Manantial, 2014. 